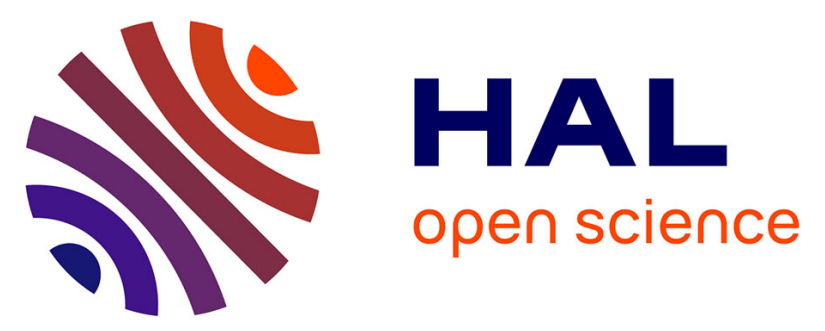

\title{
Antibacterial and cytotoxic triterpenoids from the roots of Combretum racemosum
}

\author{
Diane Patricia Apie Gossan, Abdulmagid Alabdul Magid, Philomène Akoua \\ Yao-Kouassi, Jérôme Josse, Sophie C. Gangloff, Hamid Morjani, Laurence \\ Voutquenne-Nazabadioko
}

\section{To cite this version:}

Diane Patricia Apie Gossan, Abdulmagid Alabdul Magid, Philomène Akoua Yao-Kouassi, Jérôme Josse, Sophie C. Gangloff, et al.. Antibacterial and cytotoxic triterpenoids from the roots of Combretum racemosum. Fitoterapia, 2016, 110, pp.89 - 95. 10.1016/j.fitote.2016.03.002 . hal-01833994

\section{HAL Id: hal-01833994 \\ https://hal.univ-reims.fr/hal-01833994}

Submitted on 28 Oct 2021

HAL is a multi-disciplinary open access archive for the deposit and dissemination of scientific research documents, whether they are published or not. The documents may come from teaching and research institutions in France or abroad, or from public or private research centers.
L'archive ouverte pluridisciplinaire HAL, est destinée au dépôt et à la diffusion de documents scientifiques de niveau recherche, publiés ou non, émanant des établissements d'enseignement et de recherche français ou étrangers, des laboratoires publics ou privés. 


\section{Accepted Manuscript}

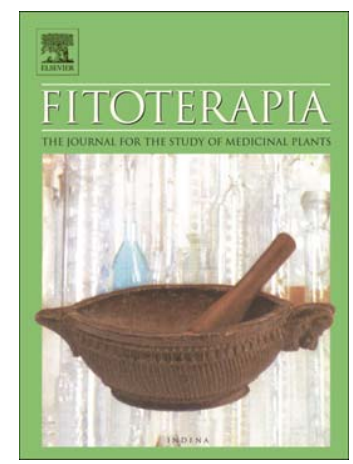

Antibacterial and cytotoxic triterpenoids from the roots of Combretum racemosum

Diane Patricia Apie Gossan, Abdulmagid Alabdul Magid, Philomène Akoua Yao-Kouassi, Jérôme Josse, Sophie C. Gangloff, Hamid Morjani, Laurence Voutquenne-Nazabadioko

PII: $\quad$ S0367-326X(16)30045-4

DOI: $\quad$ doi: $10.1016 /$ j.fitote.2016.03.002

Reference: $\quad$ FITOTE 3363

To appear in: $\quad$ Fitoterapia

Received date: $\quad 21$ January 2016

Revised date: $\quad 29$ February 2016

Accepted date: 1 March 2016

Please cite this article as: Diane Patricia Apie Gossan, Abdulmagid Alabdul Magid, Philomène Akoua Yao-Kouassi, Jérôme Josse, Sophie C. Gangloff, Hamid Morjani, Laurence Voutquenne-Nazabadioko, Antibacterial and cytotoxic triterpenoids from the roots of Combretum racemosum, Fitoterapia (2016), doi: 10.1016/j.fitote.2016.03.002

This is a PDF file of an unedited manuscript that has been accepted for publication. As a service to our customers we are providing this early version of the manuscript. The manuscript will undergo copyediting, typesetting, and review of the resulting proof before it is published in its final form. Please note that during the production process errors may be discovered which could affect the content, and all legal disclaimers that apply to the journal pertain. 


\section{Antibacterial and cytotoxic triterpenoids from the roots of Combretum racemosum}

Diane Patricia Apie Gossan ${ }^{\text {a,b }}$, Abdulmagid Alabdul Magid ${ }^{*}, \mathrm{a}$, Philomène Akoua YaoKouassi ${ }^{b}$, Jérôme Josse ${ }^{c}$, Sophie C. Gangloff ${ }^{c}$, Hamid Morjani ${ }^{\text {d }}$, Laurence VoutquenneNazabadioko ${ }^{\text {a }}$

a ICMR-UMR CNRS 7312, Groupe Isolement et Structure, Campus Sciences, Bât. 18, BP 1039, 51687 Reims Cedex 2, France

${ }^{\mathrm{b}}$ Laboratoire de Chimie Organique et de Substances Naturelles, 22 BP 582 Abidjan 22, Université Félix-Houphouët Boigny d'Abidjan-Cocody, Côte d'Ivoire

${ }^{\mathrm{c}}$ Laboratoire de microbiologie, EA 4691 «Biomatériaux et inflammation en site osseux », UFR de pharmacie, 1, rue du Maréchal-Juin, 51096 Reims cedex, France

d MEDyC UMR CNRS 7369, URCA, Faculté de Pharmacie, SFR CAP Santé, Reims, France

* Corresponding author. Tel.: +33-3-26-91-82-08; fax: +33-3-26-91-35-96. E-mail address: abdulmagid.alabdulmagid@univ-reims.fr (A. Alabdul Magid) 


\section{Abstract}

A new pentacyclic triterpenoid glucoside, together with fourteen known compounds, was isolated from the roots of Combretum racemosum (Combretaceae). The structure of the new compound was established as 28-O- $\beta$-D-glucopyranosyl-2 $\alpha, 3 \beta, 21 \beta, 23$-tetrahydroxyolean-18en-28-oate (1) on the basis of detailed spectroscopic data including MS, 1D, and 2D NMR. The inhibitory activity of compounds 1-15 against promyelocytic leukemia HL-60 and human erythromyeloblastoid leukemia K562 cell lines was evaluated. Compounds 11 (3-O- $\beta$-acetylursolic acid), 14 (betulinic acid), and 15 (quadranoside II) exhibited significant cytotoxicity, with $\mathrm{IC}_{50}$ values of 13 to $50 \mu \mathrm{M}$. Among the isolated triterpenes, compounds $\mathbf{1}, \mathbf{3}$ (arjungenin), $\mathbf{5}$ (terminolic acid), and $\mathbf{1 1}$ exhibited moderate antibacterial activity against Staphylococcus aureus, Escherichia coli and Enterococcus faecalis (MICs within a range of 64 and $256 \mu \mathrm{g} / \mathrm{mL})$.

\section{Highlights}

A new pentacyclic triterpenoid glucoside was isolated from Combretum racemosum.

Four triterpenes isolated from this plant showed antibacterial activity.

Three triterpenes showed cytotoxic activity against HL-60 and K562 cells.

Graphical abstract
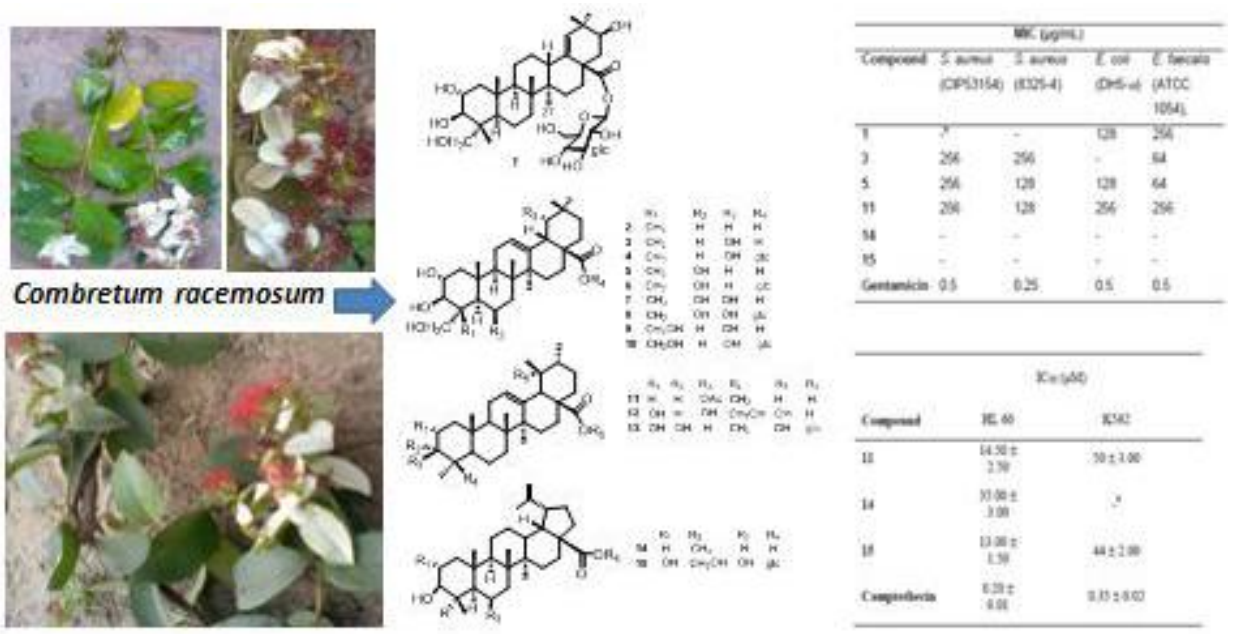
Keywords: Combretum racemosum; Combretaceae; triterpenes; antibacterial activity; cytotoxic activity.

\section{Introduction}

The Combretaceae family includes more than 600 species distributed among about 20 genera, with pantropical distribution. Combretum is one of the two most commonly occurring genera with about 370 species and is widely used in Africa [1,2]. Species of Combretum genus have been of interest in the last two decades thanks to the isolation of some compounds with highly significant activities in anticancer and anti-infectious models $[3,4,5]$. This has made the Combretum genus a very important group to search for bioactive compounds. $C$. racemosum is a straggling shrub widespread across Africa that bears a mass of crimson flowers which is very spectacular, named Christmas rose in the Southern Nigeria local English [6]. The plant has been used for several years in African traditional medical practices and as a condiment in soups. In addition to its anthelmintic [4], trypanocidal [7], and antimicrobial properties for genito-urinary and gastrointestinal infections [8], the plant is also used for the treatment of haemorrhoids, convulsive coughing, tuberculosis, toothache and male sterility [6, 9]. Furthermore, the anti-inflammatory, antiulcer, vasorelaxant, and trypanocidal properties of the C. racemosum extracts have been validated in recent pharmacological studies $[10,11,12,13$, 14]. Water or organic extracts of C. racemosum leaves also showed significant antimicrobial activities against various pathogenic microorganisms $[4,8,15]$. However, little is known about the active components conferring therapeutic properties to these extracts. Previous phytochemical analysis of $C$. racemosum extracts revealed the presence of triterpenes $[8,16]$. Up to now, the chemical constituents of the roots of $C$. racemosum have not yet been studied, which prompted us to investigate their active constituents. Thus, the present study focused on 
the isolation and purification of a new pentacyclic triterpenoid glucoside (1), together with fourteen known compounds (2-15), from the $80 \% \mathrm{MeOH}$ extract of the roots of $C$. racemosum. Their cytotoxicity against promyelocytic leukemia HL-60 and human erythromyeloblastoid leukemia cells K562 was evaluated. Additionally, their antibacterial activity against Staphylococcus aureus, Escherichia coli, and Enterococcus faecalis was also evaluated.

\section{Results and Discussion}

The $80 \%$ hydromethanol extract of the roots of $C$. racemosum was concentrated and then partitioned successively with $\mathrm{CHCl}_{3}$ and $n$-butanol $(n-\mathrm{BuOH})$. The $\mathrm{CHCl}_{3}$ soluble fraction was subjected to vacuum liquid chromatography (VLC) over silica gel followed by semiprep. HPLC to afford compounds $\mathbf{1 , 3}, \mathbf{5}, \mathbf{1 1}, \mathbf{1 2}$, and 14 whereas the $n$-BuOH soluble fraction was fractionated by VLC over RP-C 18 followed by semiprep. HPLC to obtain compounds $1,4,6$ 10, and 15 (Fig. 1). Their structures were determined by extensive spectroscopic analysis, including HSQC, HMBC, and COSY, together with chemical evidences.

Compound 1 was obtained as a colorless powder with the molecular formula $\mathrm{C}_{36} \mathrm{H}_{58} \mathrm{O}_{11}$ as deduced from the HR-ESIMS, which exhibited an ion peak at $m / z 689.3873\left([\mathrm{M}+\mathrm{Na}]^{+}\right.$, calc for 689.3877). Analysis of the ${ }^{1} \mathrm{H}$ and ${ }^{13} \mathrm{C}$ NMR spectra of $\mathbf{1}$ revealed the presence of an anomeric proton at $\delta_{\mathrm{H}} 5.54(\mathrm{~d}, J=8.2 \mathrm{~Hz})$ correlated in the HSQC spectrum with an anomeric carbon at $\delta_{\mathrm{C}} 95.9$ (Table 1). Analysis of the COSY and HSQC experiments of 1 allowed complete assignment of the glycoside proton and carbon system leading to a $\beta$-Dglucopyranoside unit [17] (Table 1). The ${ }^{1} \mathrm{H}$ NMR spectrum of $\mathbf{1}$ showed also the presence of six tertiary methyl groups $\left(\delta_{\mathrm{H}} 0.70,0.85,0.94,1.01,1.03\right.$ and 1.06$)$, one olefinic proton $\left(\delta_{\mathrm{H}}\right.$ $5.11, \mathrm{~d}, J=1.5 \mathrm{~Hz})$, one oxymethylene group $\left(\delta_{\mathrm{H}} 3.27\right.$, and 3.52 , each $\left.\mathrm{d}, J=11.2 \mathrm{~Hz}\right)$, and three oxymethine groups $\left[\delta_{\mathrm{H}} 3.72(\mathrm{td}, J=9.1,4.4 \mathrm{~Hz}), 3.36(\mathrm{~d}, J=9.1 \mathrm{~Hz})\right.$ and $3.60(\mathrm{dd}, J=13.2,3.6$ 
$\mathrm{Hz})$ ]. Its ${ }^{13} \mathrm{C}$ NMR spectrum exhibited signals for 36 carbons, including the six glucosidic carbons, one carboxyl ( $\left.\delta_{\mathrm{C}} 176.5\right)$, one double bond $\left(\delta_{\mathrm{C}} 134.3\right.$ and 137.8), one oxygenated methylene $\left(\delta_{\mathrm{C}} 66.3\right)$, and three oxygenated methines $\left(\delta_{\mathrm{C}} 70.0,72.7\right.$ and 78.5), and the other 23 carbons had chemical shifts from 13.7 to 52.5. These spectral data suggested that compound $\mathbf{1}$ was an oleanane-type triterpenoid glucoside [18]. In the HMBC spectrum, the cross-peaks observed between the methyl at $\delta_{\mathrm{H}} 0.70(\mathrm{~s}, \mathrm{H}-24)$ and signals at $\delta_{\mathrm{C}} 78.5(\mathrm{C}-3)$ and $\delta_{\mathrm{C}} 66.3(\mathrm{C}-$ 23) placed a secondary $\mathrm{OH}$ at $\mathrm{C}-3$ and a hydroxymethylene at C-4. The location of this primary hydroxyl group at C-23 was deduced from the chemical shift of C-24 at $\delta_{\mathrm{C}} 13.7$ characteristic of an axial position, and by comparison of the ${ }^{13} \mathrm{C}$ NMR spectrum with that of arjunolic acid (OH at C-23) and hyptatic acid A (OH at C-24) [18]. The ${ }^{1} \mathrm{H}-{ }^{1} \mathrm{H}$ COSY correlation observed between $\delta_{\mathrm{H}} 3.36(\mathrm{H}-3)$ and $\delta_{\mathrm{H}} 3.72$ suggested that a hydroxyl group was located at C-2. The large vicinal coupling constant value between $\mathrm{H}-2$ and $\mathrm{H}-3\left(J_{2-3}=9.1 \mathrm{~Hz}\right)$ suggested a quasi trans-diaxial relationship, like in arjunolic acid [19]. In the ROESY spectrum (Fig 2), correlations between H-3 and H-5 ( $\left.\delta_{\mathrm{H}} 1.25\right)$ confirmed the $\alpha$-axial orientation of the two protons. The ROESY correlations observed between $\mathrm{H}-2$ and protons of the methyl angular groups at $\delta_{\mathrm{H}} 0.70(\mathrm{~s}, \mathrm{H}-24)$, and $\delta_{\mathrm{H}} 1.01(\mathrm{~s}, \mathrm{H}-25)$, and between $\mathrm{H}_{3}-25$ and $\delta_{\mathrm{H}} 1.03(\mathrm{~s}, \mathrm{H}-26)$, confirmed the $\beta$-axial orientation of these $\mathrm{CH}_{3}$ and $\mathrm{H}-2$. The $\mathrm{HMBC}$ correlation between the carbon methyl signal of C-27 at $\delta_{\mathrm{C}} 15.6$ and the proton at $\delta_{\mathrm{H}} 2.32(\mathrm{brd}$ $(J=10.4 \mathrm{~Hz})$ attributed to the angular methyne proton $\mathrm{H}-13$, suggested that the aglycone was not a $\Delta^{12}$-unsaturated oleanene as in arjunolic acid [19]. The HMBC correlations between this proton $\mathrm{H}-13\left(\delta_{\mathrm{H}} 2.32\right)$ and the two ethylenic carbons at $\delta_{\mathrm{C}} 137.8(\mathrm{C}-18)$ and $134.3(\mathrm{C}-19)$ suggested a $\Delta^{18}$-unsaturated oleanene skeleton as in $2 \alpha, 3 \alpha, 24$-trihydroxyolean-18-en-28-oic acid [20]. The long range ${ }^{4} J{ }^{1} \mathrm{H}_{-}{ }^{1} \mathrm{H}$ COSY correlation observed between the olefinic proton at $\delta_{\mathrm{H}} 5.11(\mathrm{H}-19)$ and the proton $\mathrm{H}-13$ and the HMBC correlations between the olefinic proton H-19 and carbons C-13, C-17, C-20, C-21, C-29, and C-30 confirmed the position of the 
double bond at C-18 (Fig 2). This data was supported by the ROESY experiment that showed rOe effects between $\mathrm{H}-19 / \mathrm{H}-12, \mathrm{H}-19 / \mathrm{H}_{3}-29$, and $\mathrm{H}-19 / \mathrm{H}_{3}-30$.

Fig. 2. Key ROESY and HMBC relationships of compound $\mathbf{1 .}$

The comparison of ${ }^{13} \mathrm{C}$ NMR data of compound 1 with those of $2 \alpha, 3 \alpha, 24$-trihydroxyolean-18en-28-oic acid [20], an oleanane-type triterpenoid obtained from Eucalyptus exserta, indicated that these compounds differ by the presence of a hydroxyl group at C-21 and the configuration of C-2 and C-3. This was supported by the downfield shifts of C-20 $\left(\delta_{\mathrm{C}} 38.2\right)$, C-21 $\left(\delta_{\mathrm{C}} 72.7\right)$, and C-22 $\left(\delta_{\mathrm{C}} 41.1\right)$. The position of the hydroxyl group at C-21 was confirmed by the HMBC correlations observed between $\mathrm{H}-21\left(\delta_{\mathrm{H}} 3.60\right)$ and $\mathrm{C}-17, \mathrm{C}-19, \mathrm{C}-22, \mathrm{C}-20, \mathrm{C}-$ 29, and C-30. The $\alpha$-axial orientation of H-21 was justified by the value of the vicinal coupling constant H-21/H-22ax $(J=13.2 \mathrm{~Hz})$ and the ROESY correlations observed between $\mathrm{H}-21 / \mathrm{H}_{3}-29$ and $\mathrm{H}-21 / \mathrm{H}-22 \mathrm{eq}\left(\delta_{\mathrm{H}} 2.06, \mathrm{dd}, J=13.2,3.6\right)$. Full assignments of the proton and carbon resonances of the aglycone were achieved by analysis of the COSY, HSQC and HMBC spectra (Table 1). The triterpene skeleton of $\mathbf{1}$ was identified as $2 \alpha, 3 \beta, 21 \beta$, 23tetrahydroxyolean-18-en-28-oic acid. The chemical shifts of the signals due to C-3 and C-28 of aglycone, in ${ }^{13} \mathrm{C}$ NMR spectra $\left(\delta_{\mathrm{C}-3} 78.5\right.$ and $\left.\delta_{\mathrm{C}-28} 176.5\right)$, suggested the $\mathrm{C}-28$ glycosylation of 1 [18]. This was confirmed by the HMBC correlation observed between the anomeric proton of the $\beta$-D-glucopyranoside and the C-28 of aglycone. Therefore, compound $\mathbf{1}$ was assigned as 28-O- $\beta$-D-glucopyranosyl-2 $\alpha, 3 \beta, 21 \beta, 23$-tetrahydroxyolean-18-en-28-oate.

Fig.1. Chemical structures of triterpenes 1-15, isolated from Combretum racemosum. 
Table $1{ }^{1} \mathrm{H},{ }^{13} \mathrm{C}$ NMR, HMBC, and ROESY spectral data of compound $\mathbf{1}$.

\begin{tabular}{|c|c|c|c|c|c|}
\hline Position & ${ }^{1}$ H-NMR & ${ }^{13} \mathrm{C}-\mathrm{NMR}$ & DEPT & HMBC correlation & ROESY correlation \\
\hline & $\delta_{\mathrm{H}} \mathrm{m}(J$ in $\mathrm{Hz})$ & $\delta_{\mathrm{C}}$ & & & \\
\hline 1 & $\begin{array}{l}0.89 \mathrm{~m} \\
2.08 \mathrm{~m}\end{array}$ & 48.1 & $\mathrm{CH}_{2}$ & $\mathrm{C}-2, \mathrm{C}-10, \mathrm{C}-25$ & \\
\hline 2 & $3.72 \operatorname{td}(9.1,4.4)$ & 70.0 & $\mathrm{CH}$ & & H-25 \\
\hline 3 & $3.36 \mathrm{~d}(9.1)$ & 78.5 & $\mathrm{CH}$ & $\mathrm{C}-2, \mathrm{C}-23, \mathrm{C}-24$ & H-23, H-5 \\
\hline 4 & - & 44.1 & $\mathrm{C}$ & & \\
\hline 5 & $1.25 \mathrm{~m}$ & 49.3 & $\mathrm{CH}$ & $\mathrm{C}-23, \mathrm{C}-24$ & H-9 \\
\hline 6 & $\begin{array}{l}1.40 \mathrm{dd}(12.8,7.9) \\
1.65 \mathrm{dm}(12.8)\end{array}$ & 22.3 & $\mathrm{CH}_{2}$ & & \\
\hline 7 & $1.45 \mathrm{~m}$ & 35.1 & $\mathrm{CH}_{2}$ & $\mathrm{C}-26$ & \\
\hline 8 & & 41.9 & $\mathrm{C}$ & H-26, H-27 & \\
\hline 9 & $1.43 \mathrm{~m}$ & 52.5 & $\mathrm{CH}$ & $\mathrm{C}-25, \mathrm{C}-26$ & $\mathrm{H}-27$ \\
\hline 10 & - & 39.3 & $\mathrm{C}$ & $\mathrm{H}-1, \mathrm{H}-25$ & \\
\hline 11 & $\begin{array}{l}1.07 \mathrm{~m} \\
1.45 \mathrm{~m}\end{array}$ & 19.0 & $\mathrm{CH}_{2}$ & $\mathrm{C}-13$ & \\
\hline 12 & $\begin{array}{l}1.27 \mathrm{~m} \\
1.63 \mathrm{~m}\end{array}$ & 27.5 & $\mathrm{CH}_{2}$ & C-13 & \\
\hline 13 & $2.32 b r \mathrm{~d}(10.4)$ & 41.8 & $\mathrm{CH}$ & $\mathrm{H}-11, \mathrm{H}-12$ & H-26 \\
\hline 14 & - & 43.8 & $\mathrm{C}$ & $\mathrm{H}-13, \mathrm{H}-26, \mathrm{H}-27$ & \\
\hline 15 & $\begin{array}{l}1.22 \mathrm{~m} \\
1.74 \mathrm{~m}\end{array}$ & 30.3 & $\mathrm{CH}_{2}$ & C-27 & \\
\hline 16 & $\begin{array}{l}1.45 \mathrm{~m} \\
2.31 \mathrm{dd}(12.4,2.0)\end{array}$ & 35.0 & $\mathrm{CH}_{2}$ & $\mathrm{C}-17, \mathrm{C}-28$ & \\
\hline 17 & - & 51.8 & $\mathrm{C}$ & $\mathrm{H}-13, \mathrm{H}-22$ & \\
\hline 18 & - & 137.8 & $\mathrm{C}$ & $\mathrm{H}-13, \mathrm{H}-16$ & \\
\hline 19 & $5.11 \mathrm{~d}(1.5)$ & 134.3 & $\mathrm{CH}$ & C-13, C-17, C-21, C-29, C-30 & $\mathrm{H}-12, \mathrm{H}-29, \mathrm{H}-30$ \\
\hline 20 & - & 38.2 & $\mathrm{C}$ & $\mathrm{H}-29, \mathrm{H}-30$ & \\
\hline 21 & $3.60 \mathrm{dd}(13.2,3.6)$ & 72.7 & $\mathrm{CH}$ & C-30, C-29, C-20, C-17, C-22 & H-29 \\
\hline 22 & $\begin{array}{l}1.67 \mathrm{t}(13.2) \\
2.06 \mathrm{dd}(13.2,3.6)\end{array}$ & 41.1 & $\mathrm{CH}_{2}$ & $\mathrm{C}-17, \mathrm{C}-28$ & $\begin{array}{l}\mathrm{H}-18 \\
\mathrm{H}-21\end{array}$ \\
\hline 23 & $\begin{array}{l}3.27 \mathrm{~d}(11.2) \\
3.52 \mathrm{~d}(11.2)\end{array}$ & 66.3 & $\mathrm{CH}_{2}$ & $C-3, C-4, C-5$ & $\mathrm{H}-3$ \\
\hline 24 & $0.70 \mathrm{~s}$ & 13.7 & $\mathrm{CH}_{3}$ & & H-25 \\
\hline 25 & $1.01 \mathrm{~s}$ & 18.8 & $\mathrm{CH}_{3}$ & $\mathrm{C}-1, \mathrm{C}-9, \mathrm{C}-10$ & $\mathrm{H}-24$ \\
\hline 26 & $1.03 \mathrm{~s}$ & 16.6 & $\mathrm{CH}_{3}$ & C-8, C-14 & $\mathrm{H}-13$ \\
\hline 27 & $0.85 \mathrm{~s}$ & 15.6 & $\mathrm{CH}_{3}$ & C-8, C-14 & H-9 \\
\hline 28 & - & 176.5 & C & H-1', H-16, H-22 & \\
\hline 29 & $1.06 \mathrm{~s}$ & 28.3 & $\mathrm{CH}_{3}$ & $\mathrm{C}-20, \mathrm{C}-30$ & $\mathrm{H}-21$ \\
\hline & $0.94 \mathrm{~s}$ & 22.1 & $\mathrm{CH}_{3}$ & C-20, C29 & \\
\hline 28-O-glc & & & & & \\
\hline $\mathbf{1}^{\prime}$ & $5.54 \mathrm{~d}(8.2)$ & 95.9 & $\mathrm{CH}$ & $\mathrm{C}-3^{\prime}, \mathrm{C}-28$ & $\mathrm{H}-3^{\prime}, \mathrm{H}-5^{\prime}$ \\
\hline $2^{\prime}$ & $3.33 \mathrm{~m}$ & 74.1 & $\mathrm{CH}$ & C- $4^{\prime}$ & \\
\hline $\mathbf{3}^{\prime}$ & $3.36 \mathrm{t}(9.6)$ & 78.2 & $\mathrm{CH}$ & $C-1^{\prime}, C-5^{\prime}$ & $\mathrm{H}-1^{\prime}, \mathrm{H}-5^{\prime}$ \\
\hline $4^{\prime}$ & $3.39 \mathrm{t}(9.6)$ & 71.1 & $\mathrm{CH}$ & C- $2^{\prime}, C-6^{\prime}$ & \\
\hline $5^{\prime}$ & $3.40 \mathrm{~m}$ & 78.8 & $\mathrm{CH}$ & $\mathrm{C}-3^{\prime}, \mathrm{C}-1^{\prime}$ & $\mathrm{H}-1^{\prime}, \mathrm{H}-3^{\prime}$ \\
\hline $6^{\prime}$ & $3.73 \mathrm{dd}(11.6,2.1)$ & 62.4 & $\mathrm{CH}_{2}$ & $\mathrm{C}-4^{\prime}, \mathrm{C}-5^{\prime}$ & \\
\hline & $3.85 \mathrm{dd}(11.5,0.8)$ & & & & \\
\hline
\end{tabular}

Compounds 2-14 were known and their structural assignments were made by ESI-MS and 1D, and 2D NMR analysis. Their spectroscopic data (Tables 4 and 5) were in good agreement with those reported in the literature for arjunolic acid (2) [19], arjungenin (3) [21], 
arjunglucoside I (4) [21], terminolic acid (5) [22], chebuloside II (6) [23], combregenin (7) [22], combreglucoside (8) [22], bellericagenin B (9) [24], bellericaside B (10) [24], 3-O- $\beta$ acetyl-ursolic acid (11) [25, 26], 24-hydroxy-tormentic acid (12) [27], kaji-ichigoside F1 (13) [28], betulinic acid (14) [29], and quadranoside II (15) [30]. 
Table 4

${ }^{1} \mathrm{H}$ and ${ }^{13} \mathrm{C}$ NMR data of compound 2-8.

\begin{tabular}{|c|c|c|c|c|c|c|c|c|c|c|c|c|c|c|}
\hline & $\begin{array}{c}\mathbf{2} \\
\delta_{\mathrm{S}} \mathrm{m}(J \mathrm{in} \mathrm{Hz})\end{array}$ & $\delta_{\mathrm{c}}$ & $\begin{array}{c}\mathbf{3} \\
\delta_{\mathrm{U}} \mathrm{m}(J \text { in } \mathrm{Hz})\end{array}$ & $\delta_{C}$ & $\begin{array}{c}\mathbf{4} \\
\delta_{\mathrm{U}} \mathrm{m}(\mathrm{J} \text { in } \mathrm{Hz})\end{array}$ & $\delta_{\mathrm{C}}$ & $\begin{array}{c}\mathbf{5} \\
\delta_{\mathrm{U}} \mathrm{m}(J \mathrm{in} \mathrm{Hz})\end{array}$ & $\delta_{\mathrm{C}}$ & $\begin{array}{c}\mathbf{6} \\
\delta_{\mathrm{H}} \mathrm{m}(J \mathrm{in} \mathrm{Hz})\end{array}$ & $\delta_{\mathrm{c}}$ & $\begin{array}{c}\mathbf{7} \\
\delta_{\mathrm{U}} \mathrm{m}(\mathrm{J} \text { in } \mathrm{Hz})\end{array}$ & & $\begin{array}{c}\mathbf{8} \\
\delta_{\mathrm{U}} \mathrm{m}(\mathrm{J} \text { in } \mathrm{Hz})\end{array}$ & $\delta_{\mathrm{C}}$ \\
\hline 1 & $0.91 \mathrm{~m}$ & 47.5 & 0.92 brd (12.5) & 47.7 & $0.92 \mathrm{t}(12.5)$ & 47.8 & $0.88 \mathrm{t}(11.9)$ & 50.1 & $0.89 \mathrm{t}(12.6)$ & 50.1 & $0.90 \mathrm{t}(11.8)$ & 49.9 & $0.90 \mathrm{t}(12.1)$ & 49.9 \\
\hline & $1.95 \mathrm{~m}$ & & $1.93 \mathrm{dd}(12.5,4.5)$ & & $1.93 \mathrm{dd}(12.5,4.5)$ & & $1.91 \mathrm{dd}(11.9(4.4)$ & & $1.91 \mathrm{dd}(12.4,4.6)$ & & $1.88 \mathrm{dd}(11.9,5.0)$ & & $1.88 \mathrm{dd}(12.1,4.8)$ & \\
\hline 2 & $3.70 \mathrm{~m}$ & 69.7 & $3.72 \operatorname{td}(9.4,4.5)$ & 69.7 & $3.72 \mathrm{ddd}(12.5,9.7,4.5)$ & 69.7 & 3.76 td $(11.9,4.4)$ & 69.7 & $3.76 \operatorname{td}(10.9,4$ & 69.7 & $3.76 \mathrm{ddd}(11.1,9.5,5.0$ & 69.7 & 3.76 td $(10.1,4.8)$ & 69.7 \\
\hline 3 & $3.37 \mathrm{~d}(9.5)$ & 78.2 & $3.38 \mathrm{~d}(9.4)$ & 78.3 & $3.37 \mathrm{~d}(9.7)$ & 78.7 & $3.32 \mathrm{~d}(11.9)$ & 78.2 & $3.31 \mathrm{~d}(10.9)$ & 78.2 & $3.32 \mathrm{~d}(9.5)$ & 78.3 & $3.32 \mathrm{~d}(10.1)$ & 78.3 \\
\hline 4 & & 44.1 & & 44.1 & & 44.1 & & 44.8 & & 44.8 & & 44.8 & & 44.8 \\
\hline 5 & $1.31 \mathrm{~m}$ & 48.2 & $1.33 \mathrm{~m}$ & 48.4 & $1.32 \mathrm{~d}(6.5)$ & 48.4 & $1.29 \mathrm{~m}$ & 48.8 & $1.30 \mathrm{brs}$ & 49.0 & $1.33 \mathrm{~d}(1.8)$ & 49.3 & $1.33 \mathrm{~d}(1.8)$ & 49.2 \\
\hline 6 & $\begin{array}{l}1.43 \mathrm{~m} \\
1.49 \mathrm{~m}\end{array}$ & 18.6 & $\begin{array}{l}1.50 \mathrm{~m} \\
1.48 \mathrm{~m}\end{array}$ & 19.3 & $\begin{array}{l}1.45 \mathrm{~m} \\
1.48 \mathrm{~m}\end{array}$ & 19.3 & $4.40 \mathrm{brs}$ & 68.5 & $4.40 \mathrm{brs}$ & 68.5 & $4.42 \mathrm{br} \mathrm{s}$ & 68.7 & $4.42 \mathrm{br} \mathrm{s}$ & 68.8 \\
\hline 7 & $\begin{array}{l}1.31 \mathrm{~m} \\
1.63 \mathrm{~m}\end{array}$ & 33.6 & $\begin{array}{l}1.28 \mathrm{dd}(10.1,2.9) \\
1.63 \mathrm{~m}\end{array}$ & 33.3 & $\begin{array}{l}1.30 \mathrm{dd}(13.0,6.5) \\
1.62 \mathrm{~m}\end{array}$ & 33.3 & $\begin{array}{l}1.51 \mathrm{dd}(14.0,1.8) \\
1.79 \mathrm{dt}(14.0,3.3)\end{array}$ & 41.1 & $\begin{array}{l}1.51 \mathrm{dd}(14.3,2.1) \\
1.77 \mathrm{dd}(14.3,3.9)\end{array}$ & 41.0 & $\begin{array}{l}1.51 \mathrm{dd}(14.4,2.5) \\
1.81 \mathrm{dd}(14.4,4.5)\end{array}$ & 41.3 & $\begin{array}{l}1.51 \mathrm{dd}(14.4,2.5) \\
1.79 \mathrm{dd}(14.4,4.5)\end{array}$ & 41.2 \\
\hline 8 & & 40.6 & & 40.7 & & 40.9 & & 39.8 & & 39.9 & & 40.0 & & 40.1 \\
\hline $\begin{array}{l}9 \\
10\end{array}$ & $1.71 \mathrm{~m}$ & $\begin{array}{l}49.2 \\
39.1\end{array}$ & $1.86 \mathrm{t}(8.8)$ & $\begin{array}{l}49.1 \\
39.2\end{array}$ & $1.85 \mathrm{t}(8.7)$ & $\begin{array}{l}49.0 \\
39.2\end{array}$ & $1.73 \mathrm{~m}$ & $\begin{array}{l}49.3 \\
38.6\end{array}$ & $1.73 \mathrm{dd}(11.1,3.9)$ & $\begin{array}{l}49.2 \\
38.6\end{array}$ & $1.88 \mathrm{~m}$ & $\begin{array}{l}49.5 \\
38.7\end{array}$ & $1.87 \mathrm{~m}$ & $\begin{array}{l}49.5 \\
38.7\end{array}$ \\
\hline 11 & $\begin{array}{l}2.02 \mathrm{~m} \\
2.02 \mathrm{~m}\end{array}$ & 24.2 & $\begin{array}{l}2.02 \mathrm{~m} \\
2.02 \mathrm{~m}\end{array}$ & 24.9 & $\begin{array}{l}2.02 \mathrm{~m} \\
2.02 \mathrm{~m}\end{array}$ & 24.9 & $\begin{array}{l}11.98 \mathrm{~m} \\
2.11 \mathrm{~m}\end{array}$ & 24.6 & $\begin{array}{l}1.97 \mathrm{~m} \\
2.10 \mathrm{~m}\end{array}$ & 24.0 & $\begin{array}{l}2.04 \mathrm{~m} \\
2.11 \mathrm{dd}(11.0,3.9)\end{array}$ & 24.8 & $\begin{array}{l}2.04 \mathrm{~m} \\
2.11 \mathrm{dd}(10.9,3.5)\end{array}$ & 24.8 \\
\hline 12 & $5.27 b r \mathrm{~s}$ & 123.3 & $5.35 \mathrm{t}(3.4)$ & 124.7 & $5.36 \mathrm{t}(3.5)$ & 124.8 & $5.31 \mathrm{t}(3.4)$ & 123.7 & $5.33 \mathrm{t}(3.5)$ & 123.9 & $5.39 \mathrm{t}(3.5)$ & 125.0 & $5.39 \mathrm{t}(3.5)$ & 125.0 \\
\hline 13 & & 144.8 & & 144.8 & & 144.5 & & 144.7 & & 144.3 & & 144.0 & & 143.8 \\
\hline 14 & & 43.1 & & 42.7 & & 42.8 & & 43.5 & & 43.5 & & 43.2 & & 43.2 \\
\hline 15 & $\begin{array}{l}1.09 \mathrm{~m} \\
1.80 \mathrm{~m}\end{array}$ & 28.8 & $\begin{array}{l}1.02 \mathrm{~m} \\
1.62 \mathrm{~m}\end{array}$ & 29.4 & $\begin{array}{l}1.02 \mathrm{~m} \\
1.74 \mathrm{~m}\end{array}$ & 29.4 & $\begin{array}{l}1.08 \mathrm{~m} \\
1.87 \mathrm{td}(13.8,3.0)\end{array}$ & 28.8 & $\begin{array}{l}1.11 \mathrm{~m} \\
1.85 \mathrm{dd}(13.9,3.4)\end{array}$ & 28.8 & $\begin{array}{l}1.03 \mathrm{dd}(11.0,3.7) \\
1.78 \mathrm{~m}\end{array}$ & 29.4 & $\begin{array}{l}1.02 \mathrm{~m} \\
1.78 \mathrm{~m}\end{array}$ & 29.4 \\
\hline 16 & $\begin{array}{l}1.97 \mathrm{~m} \\
2.30 \mathrm{~m}\end{array}$ & 24.7 & $\begin{array}{l}1.62 \mathrm{~m} \\
2.31 \mathrm{td}(14.6,5.0)\end{array}$ & 28.6 & $\begin{array}{l}1.74 \mathrm{~m} \\
2.350\end{array}$ & 28.4 & $\begin{array}{l}1.61 \mathrm{br} \mathrm{d}(13.1) \\
2.01 \mathrm{~m}\end{array}$ & 24.6 & $\begin{array}{l}1.75 \mathrm{~m} \\
2.07 \mathrm{td}(13.9,3.4)\end{array}$ & 24.6 & $\begin{array}{l}1.63 \mathrm{~m} \\
2.30 \mathrm{td}(13.4,3.7)\end{array}$ & 28.6 & $\begin{array}{l}1.75 \mathrm{brd}(11.0) \\
2.34 \mathrm{~m}\end{array}$ & 28.5 \\
\hline 17 & & 46.9 & & 46.7 & & 47.1 & & 48.5 & & 48.0 & & 46.7 & & 47.1 \\
\hline 18 & $2.88 \mathrm{~m}$ & 41.9 & $3.08 b r \mathrm{~s}$ & 45.2 & $3.08 \mathrm{br} \mathrm{s}$ & 45.1 & $2.90 \mathrm{dd}(13.7,3.6)$ & 42.8 & $2.90 \mathrm{dd}(13.8,4.2)$ & 42.6 & $3.10 b r \mathrm{~s}$ & 45.2 & $3.09 \mathrm{brs}$ & 45.0 \\
\hline 19 & $\begin{array}{l}1.15 \mathrm{~m} \\
1.71 \mathrm{~m}\end{array}$ & 47.3 & $3.28 \mathrm{~d}(4.4)$ & 82.5 & $3.29 \mathrm{~m}$ & 82.4 & $\begin{array}{l}1.15 \mathrm{~m} \\
1.72 \mathrm{~m}\end{array}$ & 47.3 & $\begin{array}{l}1.19 \mathrm{dd}(11.3,4.4) \\
1.75 \mathrm{t}(11.3)\end{array}$ & 47.2 & $3.29 \mathrm{~d}(3.9)$ & 82.5 & $3.31 \mathrm{~d}(3.8)$ & 82.4 \\
\hline 20 & & 31.6 & & 36.0 & & 36.0 & 0 & 31.6 & & 31.5 & & 36.0 & & 36.0 \\
\hline 21 & $\begin{array}{l}1.22 \mathrm{~m} \\
1.41 \mathrm{~m}\end{array}$ & 34.9 & $\begin{array}{l}1.62 \mathrm{~m} \\
1.78 \mathrm{td}(9.9,3.0)\end{array}$ & 29.5 & $\begin{array}{l}1.68 \mathrm{dd}(9.8,3.5) \\
1.80 \operatorname{td}(9.8,3.5)\end{array}$ & 29.5 & $\begin{array}{l}1.22 \mathrm{brd}(16.2) \\
1.39 \mathrm{td}(16.2,3.9\end{array}$ & 34.9 & $\begin{array}{l}1.24 \mathrm{~m} \\
1.43 \mathrm{td}(13.7,4.0)\end{array}$ & 34.9 & $\begin{array}{l}1.02 \mathrm{dd}(13.7,3.4) \\
1.75 \mathrm{~m}\end{array}$ & 29.6 & $\begin{array}{l}1.05 \mathrm{~m} \\
1.75 \mathrm{~m}\end{array}$ & 29.6 \\
\hline 22 & $\begin{array}{l}1.56 \mathrm{~m} \\
1.76 \mathrm{~m}\end{array}$ & 34.0 & $\begin{array}{l}1.62 \mathrm{~m} \\
1.78 \mathrm{td}(9.9,3.0)\end{array}$ & 34.0 & $\begin{array}{l}1.68 \mathrm{dd}(9.8,3.5) \\
1.80 \mathrm{dd}(9.8,3.5)\end{array}$ & 33.3 & $\begin{array}{l}1.56 \mathrm{brd}(13.7) \\
1.76 \mathrm{~m}\end{array}$ & 33.9 & $\begin{array}{l}1.64 \mathrm{dt}(13.7,3.2) \\
1.75 \mathrm{dd}(13.7,3.2)\end{array}$ & 33.1 & $\begin{array}{l}1.64 \mathrm{~m} \\
1.79 \mathrm{~m}\end{array}$ & 34.0 & $\begin{array}{l}1.69 \mathrm{dd}(21.2,7.8) \\
1.80 \mathrm{dd}(21.2,4.1)\end{array}$ & 33.2 \\
\hline 23 & $\begin{array}{l}3.29 \mathrm{~d}(11.0) \\
3.53 \mathrm{~d}(11.0)\end{array}$ & 66.3 & $\begin{array}{l}3.29 \mathrm{~d}(12.2) \\
3.38 \mathrm{~d}(12.2)\end{array}$ & 66.4 & $\begin{array}{l}3.29 \mathrm{~d}(11.1) \\
3.38 \mathrm{~d}(11.1)\end{array}$ & 66.5 & $\begin{array}{l}3.46 \mathrm{~d}(11.1) \\
3.61 \mathrm{~d}(11.1)\end{array}$ & 65.9 & $\begin{array}{l}3.46 \mathrm{~d}(11.1) \\
3.60 \mathrm{~d}(11.2)\end{array}$ & 66.9 & $\begin{array}{l}3.48 \mathrm{~d}(11.0) \\
3.61 \mathrm{~d}(11.0)\end{array}$ & 66.0 & $\begin{array}{l}3.48 \mathrm{~d}(11.1) \\
3.61 \mathrm{~d}(11.1)\end{array}$ & 65.9 \\
\hline 24 & $0.72 \mathrm{~s}$ & 13.9 & $0.72 \mathrm{~s}$ & 13.8 & $0.73 \mathrm{~s}$ & 13.8 & $1.09 \mathrm{~s}$ & 15.2 & $1.08 \mathrm{~s}$ & 15.2 & $1.09 \mathrm{~s}$ & 15.2 & $1.09 \mathrm{~s}$ & 15.2 \\
\hline 25 & $1.06 \mathrm{~s}$ & 17.5 & $1.05 \mathrm{~s}$ & 17.4 & $1.05 \mathrm{~s}$ & 17.5 & $1.40 \mathrm{~s}$ & 18.9 & $1.41 \mathrm{~s}$ & 18.9 & $1.40 \mathrm{~s}$ & 18.4 & $1.40 \mathrm{~s}$ & 18.9 \\
\hline 26 & $0.85 \mathrm{~s}$ & 17.5 & $0.79 \mathrm{~s}$ & 17.8 & $0.77 \mathrm{~s}$ & 17.8 & $1.12 \mathrm{~s}$ & 19.1 & $1.09 \mathrm{~s}$ & 19.1 & $1.05 \mathrm{~s}$ & 18.2 & $1.05 \mathrm{~s}$ & 18.6 \\
\hline 27 & $1.20 \mathrm{~s}$ & 26.5 & $1.33 \mathrm{~s}$ & 25.1 & $1.33 \mathrm{~s}$ & 25.0 & $1.17 \mathrm{~s}$ & 26.5 & $1.16 \mathrm{~s}$ & 26.4 & $1.30 \mathrm{~s}$ & 25.1 & $1.30 \mathrm{~s}$ & 25.0 \\
\hline 28 & & 180.2 & & 182.4 & & 178.6 & & 181.9 & & 178.1 & & 182.3 & & 178.6 \\
\hline 29 & $0.93 \mathrm{~s}$ & 33.7 & $0.96 \mathrm{~s}$ & 28.7 & $0.96 \mathrm{~s}$ & 28.6 & $0.93 \mathrm{~s}$ & 33.6 & $0.94 \mathrm{~s}$ & 33.5 & $0.96 \mathrm{~s}$ & 28.7 & $0.97 \mathrm{~s}$ & 28.6 \\
\hline 30 & $0.97 \mathrm{~s}$ & 23.7 & $0.99 \mathrm{~s}$ & 25.1 & $0.97 \mathrm{~s}$ & 25.2 & $0.97 \mathrm{~s}$ & 24.0 & $0.96 \mathrm{~s}$ & 24.0 & $0.99 \mathrm{~s}$ & 25.2 & $0.98 \mathrm{~s}$ & 25.2 \\
\hline $\begin{array}{l}\text { glc } \\
1^{\prime}\end{array}$ & & & & & $5.40 \mathrm{~d}(8.2)$ & 95.8 & & & $5.40 \mathrm{~d}(8.1)$ & 95.8 & & & $5.39 \mathrm{~d}(8.1)$ & 95.9 \\
\hline $\begin{array}{l}T^{\prime} \\
2^{\prime}\end{array}$ & & & & & $3.34 \mathrm{dd}(8.9,8.2)$ & 73.9 & & & $3.35 \mathrm{dd}(9.1,8.1)$ & 73.9 & & & $3.35 \mathrm{dd}(9.1,8.1)$ & 73.9 \\
\hline $\mathbf{3}^{\prime}$ & & & & & $3.42 \mathrm{t}(8.9)$ & 78.3 & & & $3.42 \mathrm{t}(9.1)$ & 78.3 & & & $3.43 \mathrm{t}(9.1)$ & 78.3 \\
\hline $4^{\prime}$ & & & & & $3.37 \mathrm{t}(8.9)$ & 71.1 & & & $3.39 \mathrm{t}(9.1)$ & 71.4 & & & $3.39 \mathrm{t}(9.1)$ & 71.1 \\
\hline $5^{\prime}$ & & & & & $3.37 \mathrm{~m}$ & 78.4 & & & $3.37 \mathrm{~m}$ & 78.6 & & & $3.37 \mathrm{~m}$ & 78.7 \\
\hline $6^{\prime}$ & & & & & $3.70 \mathrm{dd}(12.2,4.2)$ & 62.4 & & & $3.70 \mathrm{dd}(12.1,4.4)$ & 62.4 & & & $3.71 \mathrm{dd}(12.1,4.2)$ & 62.4 \\
\hline & & & & & $3.84 \mathrm{dd}(12.2,1.6)$ & & & & $3.84 \mathrm{dd}(12.1,1.6)$ & & & & $3.84 \mathrm{dd}(12.1,1.3)$ & \\
\hline
\end{tabular}


Table 5

${ }^{1} \mathrm{H}$ and ${ }^{13} \mathrm{C}$ NMR data of compound 9-15.

\begin{tabular}{|c|c|c|c|c|c|c|c|c|c|c|c|c|c|c|}
\hline & 9 & & 10 & & 11 & & 12 & & 13 & & 14 & & 15 & \\
\hline & $\delta_{\mathrm{H}} \mathrm{m}(J$ in $\mathrm{Hz})$ & $\delta_{\mathrm{C}}$ & $\delta_{\mathrm{H}} \mathrm{m}(J$ in $\mathrm{Hz})$ & $\delta_{\mathrm{C}}$ & $\delta_{\mathrm{H}} \mathrm{m}(J$ in $\mathrm{Hz})$ & $\delta_{\mathrm{C}}$ & $\delta_{\mathrm{H}} \mathrm{m}(J$ in $\mathrm{Hz})$ & $\delta_{\mathrm{C}}$ & $\delta_{\mathrm{H}} \mathrm{m}(\mathrm{J}$ in $\mathrm{Hz})$ & $\delta_{\mathrm{C}}$ & $\delta_{\mathrm{H}} \mathrm{m}(\mathrm{J}$ in $\mathrm{Hz})$ & $\delta_{\mathrm{C}}$ & $\delta_{\mathrm{H}} \mathrm{m}(\mathrm{J}$ in $\mathrm{Hz})$ & $\delta_{c}$ \\
\hline \multirow[t]{2}{*}{1} & $0.91 \mathrm{dd}(12.4,5.9)$ & 47.6 & $0.93 \mathrm{~m}$ & 47.6 & $1.11 \mathrm{~m}$ & 38.3 & $0.94 \mathrm{t}(12.9)$ & 47.8 & $1.30 \mathrm{~m}$ & 42.6 & $0.91 \mathrm{~m}$ & 38.9 & $0.83 \mathrm{t}(11.8)$ & 50.2 \\
\hline & $1.93 \mathrm{dd}(12.4,4.5)$ & & $1.94 \mathrm{~m}$ & & $1.67 \mathrm{~m}$ & & $1.98 \mathrm{dd}(12.9,4.5)$ & & $1.60 \mathrm{dt}(12.1,4.0)$ & & $1.69 \mathrm{~m}$ & & $1.99 \mathrm{~m}$ & \\
\hline 2 & 3.85 ddd $(12.5,9.7,4.5)$ & 69.8 & $3.86 \mathrm{~m}$ & 69.8 & $1.65 \mathrm{~m}$ & 23.6 & 3.80 ddd $(12.9,9.5,4.5)$ & 69.6 & $3.96 \mathrm{~m}$ & 67.2 & $1.61 \operatorname{td}(11.4,3.2)$ & 27.4 & $3.75 \operatorname{td}(9.6,4.7)$ & 70.0 \\
\hline 3 & $3.48 \mathrm{~d}(9.7)$ & 79.5 & $3.48 \mathrm{~d}(9.7)$ & 79.5 & $4.52 \mathrm{~d}(9.2)$ & 80.9 & $3.08 \mathrm{~d}(9.5)$ & 86.0 & $3.34 \mathrm{~m}$ & 80.1 & $3.21 \mathrm{~d}(11.4)$ & 79.0 & $3.30 \mathrm{~d}(9.6)$ & 78.2 \\
\hline 4 & & 48.2 & & 48.2 & & 37.7 & & 44.4 & & 39.5 & & 38.7 & & 44.8 \\
\hline 5 & $1.45 \mathrm{~m}$ & 48.4 & $1.43 \mathrm{~m}$ & 48.5 & $0.87 \mathrm{~m}$ & 55.3 & $0.99 \mathrm{~m}$ & 57.2 & $1.28 \mathrm{~m}$ & 49.2 & $0.70 \mathrm{~m}$ & 55.4 & $1.23 b r \mathrm{~s}$ & 49.3 \\
\hline \multirow[t]{2}{*}{6} & $1.44 \mathrm{dd}(9.1,6.6)$ & 19.8 & $1.43 \mathrm{~m}$ & 19.8 & $1.39 \mathrm{~m}$ & 18.2 & $1.30 \mathrm{~m}$ & 27.3 & $1.45 \mathrm{dd}(12.1,4.0)$ & 19.3 & $1.40 \mathrm{~m}$ & 18.3 & $4.36 \mathrm{brs}$ & 68.7 \\
\hline & $1.63 \mathrm{~m}$ & & $1.61 \mathrm{~m}$ & & $1.55 \mathrm{~m}$ & & $1.65 \mathrm{~m}$ & & & & $1.54 \mathrm{~m}$ & & & \\
\hline \multirow{2}{*}{7} & $1.28 \mathrm{~m}$ & 33.7 & $1.69 \mathrm{~m}$ & 33.3 & $1.36 \mathrm{~m}$ & 32.8 & $1.35 \mathrm{~m}$ & 34.4 & $1.34 \mathrm{~m}$ & 34.0 & $1.39 \mathrm{~m}$ & 34.3 & $1.60 \mathrm{dd}(12.1,2.3)$ & 42.4 \\
\hline & $1.63 \mathrm{~m}$ & & $1.80 \mathrm{~m}$ & & $1.51 \mathrm{~m}$ & & $1.55 \mathrm{~m}$ & & $1.60 \mathrm{dd}(12.1,4.0)$ & & $1.69 \mathrm{~m}$ & & $1.69 \mathrm{~m}$ & \\
\hline 8 & & 40.7 & & 40.9 & & 39.5 & & 41.1 & & 41.4 & & 40.7 & & 43.8 \\
\hline 9 & $1.85 \mathrm{t}(9.1)$ & 49.9 & $1.84 \mathrm{~m}$ & 49.3 & $1.56 \mathrm{~m}$ & 47.5 & $1.76 \mathrm{t}(11.9)$ & 49.2 & $1.86 \mathrm{~m}$ & 48.2 & $1.29 \mathrm{~m}$ & 50.9 & $1.48 \mathrm{~m}$ & 52.6 \\
\hline 10 & & 39.0 & & 39.0 & & 36.9 & & 39.1 & & 39.4 & & 37.0 & & 38.9 \\
\hline 11 & $2.02 \mathrm{~m}$ & 25.1 & $2.02 \mathrm{~m}$ & 25.2 & $1.94 \mathrm{~m}$ & 23.3 & $2.04 \mathrm{~m}$ & 25.0 & $2.03 \mathrm{~m}$ & 24.8 & $1.29 \mathrm{~m}$ & 20.9 & $1.48 \mathrm{~m}$ & 22.3 \\
\hline 12 & $5.34 \mathrm{t}(4.4)$ & 124.6 & $5.35 \mathrm{t}(3.5)$ & 124.7 & $5.26 \mathrm{t}(3.4)$ & 125.8 & $5.32 \mathrm{t}(3.5)$ & 129.1 & $5.34 \mathrm{t}(3.5)$ & 129.6 & $\begin{array}{l}1.05 \mathrm{dd}(12.7,8.3) \\
1.72 \mathrm{~m}\end{array}$ & 25.5 & $\begin{array}{l}1.10 \mathrm{dd}(12.8,6.3) \\
1.78 \mathrm{~m}\end{array}$ & 26.9 \\
\hline 13 & & 144.7 & & 144.5 & & 138.0 & & 140.2 & & 139.7 & $2.21 \mathrm{td}(12.6,3.6)$ & 38.4 & $2.45 \operatorname{td}(11.7,2.2)$ & 38.4 \\
\hline 14 & & 42.6 & & 42.7 & & 41.9 & & 42.6 & & 42.8 & & 42.5 & & 41.2 \\
\hline \multirow[t]{2}{*}{15} & $1.01 \mathrm{~m}$ & 29.4 & $1.04 \mathrm{~m}$ & 29.4 & $1.11 \mathrm{~m}$ & 28.0 & $1.02 \mathrm{~m}$ & 29.6 & $1.03 \mathrm{~m}$ & 29.7 & $1.21 \mathrm{dt}(13.5,2.7)$ & 29.4 & $1.20 \mathrm{~m}$ & 30.9 \\
\hline & $1.78 \operatorname{td}(11.1,2.8)$ & & $1.80 \mathrm{~m}$ & & $1.89 \mathrm{~m}$ & & $1.83 \mathrm{~m}$ & & $1.85 \mathrm{~m}$ & & $1.54 \mathrm{~m}$ & & $1.64 \mathrm{dd}(11.2,3.3)$ & \\
\hline 16 & $1.63 \mathrm{~m}$ & 28.6 & $1.75 \mathrm{~m}$ & 28.4 & $1.68 \mathrm{~m}$ & 24.1 & $1.26 \mathrm{~m}$ & 27.3 & $1.65 \mathrm{dd}(13.4,3.7)$ & 26.5 & & 32.2 & $1.47 \mathrm{dd}(9.6,4.0)$ & 32.7 \\
\hline 17 & $2.32 \operatorname{td}(11.1,2.8)$ & 46.7 & $2.35 \mathrm{~m}$ & 47.1 & $1.68 \mathrm{~m}$ & 47.9 & $1.15 \mathrm{~m}$ & 48.7 & $2.64 \mathrm{~m}$ & 49.3 & $2.29 \mathrm{dt}(12.8,3.2)$ & 56.3 & $2.37 \mathrm{dt}(9.7,3.2)$ & 57.9 \\
\hline 18 & $3.07 \mathrm{~d}(3.6)$ & 45.2 & $3.07 \mathrm{brs}$ & 45.1 & $2.21 \mathrm{~d}(11.0)$ & 52.6 & $2.53 \mathrm{br} \mathrm{s}$ & 55.1 & $2.54 b r \mathrm{~s}$ & 55.0 & $1.63 \mathrm{t}(11.2)$ & 50.5 & $1.70 \mathrm{t}(11.1)$ & 50.7 \\
\hline 19 & $3.27 \mathrm{~d}(3.6)$ & 82.4 & $3.29 \mathrm{~d}(3.6)$ & 82.4 & $1.36 \mathrm{~m}$ & 39.0 & & 73.6 & & 73.6 & $3.02 \operatorname{td}(11.2,5.1)$ & 49.3 & $3.04 \operatorname{td}(11.1,5.0)$ & 48.3 \\
\hline 20 & & 36.0 & & 36.0 & $1.04 \mathrm{~m}$ & 38.8 & $1.37 \mathrm{~m}$ & 43.1 & $1.37 \mathrm{~m}$ & 43.0 & $1.43 \mathrm{~m}$ & 150.4 & & 151.8 \\
\hline \multirow[t]{2}{*}{21} & $1.01 \mathrm{~m}$ & 29.5 & $\begin{array}{l}1.04 \mathrm{~m} \\
1.75 \mathrm{~m}\end{array}$ & 29.5 & $1.34 \mathrm{~m}$ & 30.6 & $1.31 \mathrm{dd}(9.0,6.8)$ & 30.8 & $1.26 \mathrm{~m}$ & 27.2 & $1.49 \mathrm{~m}$ & 30.6 & $1.40 \mathrm{~m}$ & 31.4 \\
\hline & $1.63 \mathrm{~m}$ & & $1.75 \mathrm{~m}$ & & $1.54 \mathrm{~m}$ & & & & $1.75 \mathrm{~m}$ & & $2.00 \mathrm{~m}$ & & $1.94 \mathrm{~m}$ & \\
\hline 22 & $\begin{array}{l}1.63 \mathrm{~m} \\
1.80 \mathrm{td}(11.1,3.4)\end{array}$ & 34.0 & $\begin{array}{l}1.30 \mathrm{~m} \\
1.60 \mathrm{~m}\end{array}$ & 33.6 & $\begin{array}{l}1.65 \mathrm{~m} \\
1.75 \mathrm{dt}(12.6,3.4)\end{array}$ & 36.7 & $\begin{array}{l}1.65 \mathrm{~m} \\
1.75 \mathrm{dd}(12.5,6.5)\end{array}$ & 39.1 & $\begin{array}{l}1.65 \mathrm{dd}(13.4,3.7) \\
1.80 \mathrm{~m}\end{array}$ & 38.3 & $\begin{array}{l}0.99 \mathrm{~m} \\
1.99 \mathrm{~m}\end{array}$ & 37.2 & $\begin{array}{l}1.49 \mathrm{~m} \\
2.02 \mathrm{~m}\end{array}$ & 37.5 \\
\hline 23 & $\begin{array}{l}3.54 \mathrm{~d}(11.6) \\
4.08 \mathrm{~d}(11.6)\end{array}$ & 64.5 & $\begin{array}{l}3.53 \mathrm{~d}(11.6) \\
4.08 \mathrm{~d}(11.6)\end{array}$ & 64.5 & $0.89 \mathrm{~s}$ & 28.1 & $1.26 \mathrm{~s}$ & 23.8 & $1.01 \mathrm{~s}$ & 29.2 & $0.78 \mathrm{~s}$ & 28.0 & $\begin{array}{l}3.46 \mathrm{~d}(11.1) \\
3.59 \mathrm{~d}(11.1)\end{array}$ & 65.9 \\
\hline 24 & $\begin{array}{l}3.65 \mathrm{~d}(11.5) \\
4.07(11.5)\end{array}$ & 62.7 & $\begin{array}{l}3.65 \mathrm{~d}(11.4) \\
4.07 \mathrm{~d}(11.4)\end{array}$ & 62.7 & $0.87 \mathrm{~s}$ & 16.7 & $\begin{array}{l}3.41 \mathrm{~d}(11.2) \\
4.06 \mathrm{~d}(11.2)\end{array}$ & 66.2 & $0.89 \mathrm{~s}$ & 22.5 & $0.84 \mathrm{~s}$ & 15.4 & $1.06 \mathrm{~s}$ & 15.0 \\
\hline 25 & $1.04 \mathrm{~s}$ & 17.3 & $1.04 \mathrm{~s}$ & 17.4 & $0.98 \mathrm{~s}$ & 15.5 & $1.01 \mathrm{~s}$ & 17.5 & $1.02 \mathrm{~s}$ & 17.0 & $0.96 \mathrm{~s}$ & 16.1 & $1.30 \mathrm{~s}$ & 19.8 \\
\hline 26 & $0.78 \mathrm{~s}$ & 17.7 & $0.75 \mathrm{~s}$ & 17.7 & $0.80 \mathrm{~s}$ & 17.0 & $0.80 \mathrm{~s}$ & 17.5 & $0.80 \mathrm{~s}$ & 17.7 & $1.00 \mathrm{~s}$ & 16.0 & $1.29 \mathrm{~s}$ & 17.2 \\
\hline 27 & $1.33 \mathrm{~s}$ & 25.1 & $1.32 \mathrm{~s}$ & 25.2 & $1.10 \mathrm{~s}$ & 23.6 & $1.36 \mathrm{~s}$ & 24.8 & $1.37 \mathrm{~s}$ & 24.8 & & 14.7 & $1.00 \mathrm{~s}$ & 15.3 \\
\hline 28 & & 182.3 & & 178.6 & & 183.1 & & 180.0 & & 178.6 & & 179.8 & & 176.2 \\
\hline 29 & $0.96 \mathrm{~s}$ & 28.7 & $0.96 \mathrm{~s}$ & 28.6 & $0.88 \mathrm{~d}(5.2)$ & 17.1 & $1.21 \mathrm{~s}$ & 27.1 & $1.23 \mathrm{~s}$ & 27.1 & $\begin{array}{l}4.63 b r \mathrm{~s} \\
4.75 b r \mathrm{~s}\end{array}$ & 109.7 & $\begin{array}{l}4.63 \mathrm{br} \mathrm{s} \\
4.75 \mathrm{br} \mathrm{s}\end{array}$ & 110.3 \\
\hline $\begin{array}{l}30 \\
\text { glc }\end{array}$ & $0.99 \mathrm{~s}$ & 25.1 & $0.97 \mathrm{~s}$ & 25.0 & $\begin{array}{l}0.96 \mathrm{~d}(5.7) \\
\text { Ac. }\end{array}$ & 21.3 & $0.95 \mathrm{~d}(6.7)$ & 16.6 & $0.96 \mathrm{~s}$ & 16.6 & $1.73 \mathrm{~s}$ & 19.4 & $1.73 \mathrm{~s}$ & 19.5 \\
\hline $\mathbf{1}^{\prime}$ & & & $5.39 \mathrm{~d}(8.1)$ & 95.8 & $2.07 \mathrm{~s}$ & 21.2 & & & $5.34 \mathrm{~d}(8.2)$ & & & & $5.52 \mathrm{~d}(8.2)$ & 95.2 \\
\hline $2^{\prime}$ & & & $3.35 \mathrm{dd}(9.2,8.1)$ & 73.9 & & 171.0 & & & $3.34 \mathrm{dd}(8.6,8.2)$ & & & & $3.34 \mathrm{dd}(8.5,8.1)$ & 74.1 \\
\hline $\mathbf{3}^{\prime}$ & & & $3.42 \mathrm{t}(9.2)$ & 78.3 & & & & & $3.42 \mathrm{t}(8.6)$ & & & & $3.45 \mathrm{t}(8.5)$ & 78.4 \\
\hline $4^{\prime}$ & & & $3.38 \mathrm{t}(9.2)$ & 71.1 & & & & & $3.37 \mathrm{t}(8.6)$ & & & & $3.40 \mathrm{t}(8.5)$ & 71.1 \\
\hline $5^{\prime}$ & & & $3.37 \mathrm{~m}$ & 78.7 & & & & & $3.35 \mathrm{~m}$ & & & & $3.37 \mathrm{~m}$ & 78.7 \\
\hline $6^{\prime}$ & & & $3.70 \mathrm{~m}$ & 62.4 & & & & & $3.70 \mathrm{dd}(11.9,4.7)$ & & & & $3.72 \mathrm{dd}(12.1,4.4)$ & 62.4 \\
\hline & & & $3.84 \mathrm{dd}(12.7,1.5)$ & & & & & & $3.82 \mathrm{dd}(11.9,2.0)$ & & & & $3.86 \mathrm{dd}(12.1,1.1)$ & \\
\hline
\end{tabular}


A serial dilution technique using 96-well microtiter plates was used to check the MIC of the pure compounds (1-15) against Staphylococcus aureus (CIP 53154), S. aureus (8325-4) and Enterococcus faecalis (ATCC 1054), and Escherichia coli (DH5- $\alpha$ ) (Table 2). The four compounds 1, 3, 5 and $\mathbf{1 1}$ showed antimicrobial activity against the four bacteria. Terminolic acid (5) was the most active with MIC values of $64 \mu \mathrm{g} / \mathrm{mL}$ against $E$. faecalis and $128 \mu \mathrm{g} / \mathrm{mL}$ against E. coli and S. aureus (8325-4). Compound 1 showed a low antibacterial activity against E. faecalis (MIC $256 \mu \mathrm{g} / \mathrm{mL})$ and E. coli $(128 \mu \mathrm{g} / \mathrm{mL})$. Arjungenin (3) showed also moderate activity against E. faecalis, whereas compound $\mathbf{1 1}$ was the less active compound. Comparison of the relation structure activity of the compound with antibacterial activity (compounds 3 and 5) with compounds 4 and $\mathbf{6}$ suggested that glucosylation at C-28 of terminolic acid and arjungenin was not favorable for the antibacterial activity.

Table 2

MIC values of compounds $\mathbf{1 - 1 5}$ against four bacteria strains. ${ }^{\text {a }}$

\begin{tabular}{lllll}
\hline \multicolumn{5}{c}{ MIC $(\mu \mathrm{g} / \mathrm{mL})$} \\
\hline Compound & $\begin{array}{l}\text { S. aureus } \\
(\text { CIP53154) }\end{array}$ & $\begin{array}{l}\text { S. aureus } \\
(8325-4)\end{array}$ & $\begin{array}{l}\text { E. coli } \\
(\mathrm{DH} 5-\alpha)\end{array}$ & $\begin{array}{l}\text { E. faecalis } \\
(\text { ATCC 1054), }\end{array}$ \\
\hline $\mathbf{1}$ & $-\mathrm{b}$ & - & 128 & 256 \\
$\mathbf{3}$ & 256 & 256 & - & 64 \\
$\mathbf{5}$ & 256 & 128 & 128 & 64 \\
$\mathbf{1 1}$ & 256 & 128 & 256 & 256 \\
$\mathbf{1 4}$ & - & - & - & - \\
$\mathbf{1 5}$ & - & - & - & - \\
Gentamicin & 0.5 & 0.25 & 0.5 & 0.5 \\
\hline
\end{tabular}

${ }^{\mathrm{a}}$ No microbial growth inhibition at $512 \mu \mathrm{g} / \mathrm{mL}$ for compounds $\mathbf{2 , 4 , 6 - 1 0}, \mathbf{1 2}$, and 13.

b -: No microbial growth inhibition at $256 \mu \mathrm{g} / \mathrm{mL}$.

Additionally, compounds 1-15 were evaluated for their inhibitory effects on the proliferation of the promyelocytic leukemia (HL-60) and human erythromyeloblastoid leukemia (K562) cells (Table 3). Only compounds 11, 14 and 15 showed moderate cytotoxic activity against HL-60 with $\mathrm{IC}_{50}$ values of $14.5,35$ and $13 \mu \mathrm{M}$, respectively. Compounds $\mathbf{1 1}$ and $\mathbf{1 5}$ also displayed a moderate cytotoxic activity against $\mathrm{K} 562$ with $\mathrm{IC}_{50}$ values of 50 and $44 \mu \mathrm{M}$, respectively. 


\section{Table 3}

Cytotoxic activities of compounds 1-15 against HL 60 and K562 cell lines. ${ }^{\text {a }}$

\begin{tabular}{lcc}
\hline & \multicolumn{2}{c}{$\mathrm{IC}_{50}(\mu \mathrm{M})$} \\
\hline Compound & HL 60 & K562 \\
\hline $\mathbf{1 1}$ & $14.50 \pm 2.50$ & $50 \pm 3.00$ \\
$\mathbf{1 4}$ & $35.00 \pm 3.00$ & $-^{\mathrm{a}}$ \\
$\mathbf{1 5}$ & $13.00 \pm 1.50$ & $44 \pm 2.00$ \\
Camptothecin & $0.20 \pm 0.01$ & $0.35 \pm 0.02$ \\
\hline a $50 \%$ inhibition not achieved at $50 \mu \mathrm{M}$ for compounds $\mathbf{1 - 1 0}, \mathbf{1 2}$, and 13.
\end{tabular}

The overall results may support the use of this plant in traditional medicine for the treatment of gastric disorders and microbial infections $[4,6,8,9]$.

\section{Experimental}

\subsection{General experimental procedures}

NMR spectra were carried in $\mathrm{CD}_{3} \mathrm{OD}$ on Bruker Avance DRX III 500 instruments $\left({ }^{1} \mathrm{H}\right.$ at 500 $\mathrm{MHz}$ and ${ }^{13} \mathrm{C}-\mathrm{Jmod}$ at $125 \mathrm{MHz}$ ). HR-ESI-MS experiments were performed using a Micromass Q-TOF micro instrument (Manchester, UK). Optical rotations were determined in $\mathrm{MeOH}$ with a Perkin-Elmer 341 polarimeter. TLC was performed on pre-coated silica-gel 60 $\mathrm{F}_{254}$ Merck. CC was carried out on Kieselgel 60 (63-200 mesh), or LiChroprep RP-18 (40-63 $\mu \mathrm{m})$ Merck. HPLC was performed on a Dionex apparatus equipped with an ASI-100 autosampler, an Ultimate 3000 pump, a diode array detector UVD 340S and Chromeleon software. $\mathrm{C}_{18}$ reversed phase column (Phenomenex 250x15 mm, Luna $5 \mu$ ) was used for semipreparative HPLC with binary gradient eluent $\left(\mathrm{H}_{2} \mathrm{O}(\mathrm{pH} 2.4\right.$ with TFA); $\mathrm{MeOH})$ and a flow rate of $3 \mathrm{~mL} / \mathrm{min}$; the chromatogram was monitored at 205, 225, 250, and $350 \mathrm{~nm}$.

\subsection{Plant material}

The roots of Combretum racemosum P. Beauv. were collected in Grand-Alépé (South-East of Yamoussoukro, Ivory Coast), in October 2009. The plant was identified by Pr. Laurent AKEASSI of FHB University and a voucher specimen (No Aké-Assi-Sn) has been deposited in the 
herbarium of the National Center of Floristic of University of FHB University of AbidjanCocody (Ivory Coast).

\subsection{Extraction and isolation}

The dried and powdered roots of $C$. racemosum $(750 \mathrm{~g})$ were macerated for $24 \mathrm{~h}$ with $15 \mathrm{~L}$ of EtOAc to afford $5 \mathrm{~g}$ of EtOAc extract. After drying, the resulting powdered material was macerated with $\mathrm{MeOH} 80 \%(15 \mathrm{~L})$ for $24 \mathrm{~h}$ and then boiled for $3 \mathrm{~h}$. After filtration, the organic phase was concentrated to $1 \mathrm{~L}$ under reduced pressure to remove $\mathrm{MeOH}$. The resulting aqueous solution was sequentially extracted three times with $\mathrm{CHCl}_{3}$ and $n$-BuOH to give the $\mathrm{CHCl}_{3}$ soluble fraction (A) $(14.5 \mathrm{~g})$ and the $n-\mathrm{BuOH}$ soluble fraction (B) (22.1 g). Fraction A was subjected to vacuum liquid chromatography (VLC) on silica gel $(9 \times 5 \mathrm{~cm})$ eluted successively with $1 \mathrm{~L}$ of $0 \%, 1 \%, 2 \%, 3 \%, 5 \%, 10 \%, 15 \%, 20 \%, 30 \%$, and $50 \% \mathrm{MeOH}$ in $\mathrm{CHCl}_{3}$ to give subfractions $\mathrm{A}_{1}-\mathrm{A}_{10}$, respectively. The fraction $\mathrm{A}_{2}(1.125 \mathrm{~g})$ was fractionated by silica gel $\mathrm{CC}$, using a gradient of $\mathrm{CHCl}_{3}-\mathrm{MeOH}(1: 0$ to $95: 5)$ to give compound $\mathbf{1 4}$ (21 mg). Fractions eluted with $\mathrm{CHCl}_{3}-\mathrm{MeOH}$ (98:2) were further purified by silica gel $\mathrm{CPP}$ using $\mathrm{CHCl}_{3}-\mathrm{MeOH}(98: 2)$ as eluent to give $11(7 \mathrm{mg})$ and $\mathbf{1 6}(10 \mathrm{mg})$. The fractions $\mathrm{A}_{7}$ and $\mathrm{A}_{8}$ (3.3 g) were fractionated by RP-18 CC $(3.5 \times 26 \mathrm{~cm})$, using a gradient of $\mathrm{MeOH}-\mathrm{H}_{2} \mathrm{O}(5: 5$ to 8:2) to give compound 7 (76 mg) eluted with $\mathrm{MeOH}-\mathrm{H}_{2} \mathrm{O}$ (55:45), and 3 (255 mg) eluted with $\mathrm{MeOH}-\mathrm{H}_{2} \mathrm{O}$ (7:3). Fractions eluted with $\mathrm{MeOH}-\mathrm{H}_{2} \mathrm{O}$ (75:25).were purified by semipreparative HPLC using a gradient of $\mathrm{MeOH}$ (from $73 \%$ to $80 \%$ in $30 \mathrm{~min}$ ) to give compounds 12 (Rt $13.5 \mathrm{~min} ; 6 \mathrm{mg}$ ), 5 (Rt $15.5 \mathrm{~min} ; 6 \mathrm{mg}$ ), and 2 (Rt $18.5 \mathrm{~min} ; 6 \mathrm{mg}$ ).

Fraction B was subjected to VLC on RP18 $(9 \times 5 \mathrm{~cm})$, eluted successively with1 L of 20, 40, 60 , 80, and $100 \% \mathrm{MeOH}$ in $\mathrm{H}_{2} \mathrm{O}$, to give subfractions $\mathrm{B}_{1}$ to $\mathrm{B}_{5}$, respectively. The fraction $\mathrm{B}_{3}$ (5.5 g) was fractionated by $\mathrm{RP}_{18} \mathrm{CC}(4.5 \times 20 \mathrm{~cm})$, using a gradient of $\mathrm{MeOH}-\mathrm{H}_{2} \mathrm{O}$ (4:6 to 8:2). Fractions eluted with $\mathrm{MeOH}-\mathrm{H}_{2} \mathrm{O}$ (5:5) (1.7 g) were purified by silica gel CC using a gradient of $\mathrm{CHCl}_{3}-\mathrm{MeOH}-\mathrm{H}_{2} \mathrm{O}$ (9:1:0 to $\left.14: 6: 1\right)$. Fractions eluted with $\mathrm{CHCl}_{3}-\mathrm{MeOH}$ (85:15) 
(92 mg) were purified by semipreparative HPLC using the gradient of $\mathrm{MeOH}$ (from $62 \%$ to $68 \%$ in $30 \mathrm{~min}$ ) to give compounds 1 ( $R \mathrm{t} 16.0 \mathrm{~min} ; 6 \mathrm{mg})$ and 4 ( $R \mathrm{t} 17.3 \mathrm{~min} ; 14 \mathrm{mg})$. Fractions eluted with $\mathrm{CHCl}_{3}-\mathrm{MeOH}$ (8:2) (626 mg) were purified by silica gel $\mathrm{CC}$ using $\mathrm{CHCl}_{3}-\mathrm{MeOH}$ (9:1 to 8:2) and then fraction eluted with $\mathrm{CHCl}_{3}-\mathrm{MeOH}(85: 15)$ was further purified by silica gel CPP using $\mathrm{CHCl}_{3}-\mathrm{MeOH}-\mathrm{H}_{2} \mathrm{O}$ (75:25:2) as eluent to give 8 (28 $\mathrm{mg}$ ) and 10 (10 mg). Fractions eluted with $\mathrm{MeOH}-\mathrm{H}_{2} \mathrm{O}$ (6:4) were fractionated by $\mathrm{CC}$ on silica gel using a gradient of $\mathrm{CHCl}_{3}-\mathrm{MeOH}(1: 0$ to $8: 2)$ to give $\mathbf{1 3}(5 \mathrm{mg})$. Fractions eluted with $\mathrm{CHCl}_{3}-$ $\mathrm{MeOH}(9: 1)$ were purified by semiprep. HPLC using $\mathrm{MeOH}$ increasing from $62 \%$ to $68 \%$ in $30 \mathrm{~min}$ to give compounds 7 (Rt $14.5 \mathrm{~min} ; 9 \mathrm{mg}$ ) and 9 (Rt $16.5 \mathrm{~min} ; 5 \mathrm{mg}$ ) whereas frs eluted with $\mathrm{CHCl}_{3}-\mathrm{MeOH}(8: 2)$ were purified by semiprep. HPLC using $\mathrm{MeOH}$ increasing from $60 \%$ to $65 \%$ in $30 \mathrm{~min}$ to give compounds $\mathbf{6}(R \mathrm{t} 21.5 \mathrm{~min} ; 19 \mathrm{mg})$ and 15 (Rt $18.3 \mathrm{~min} ; 35$ $\mathrm{mg})$.

\subsection{Sugar analysis and determination of absolute configuration}

A part of the fractions A and B (200 mg each) was refluxed with TFA $2 \mathrm{~N}$ ( $25 \mathrm{~mL})$ for $4 \mathrm{~h}$. After filtration, the mixture was extracted with EtOAc $(3 \times 25 \mathrm{~mL})$ and the acid aq layer was evaporated. The residue was purified by prep. HPLC on a Rezex ROA column with $\mathrm{H}_{2} \mathrm{SO}_{4}$ $2.5 \mathrm{mM}$ as solvent to yield glucose ( $R \mathrm{t}$ 9.74). The glucose fraction was then neutralized with $\mathrm{NaOH} 50 \mathrm{mM}$ and freeze-dried. The residues were solubilized in pyridine and soln. were filtrated and then evaporated. Glucose was dissolved in hexane-EtOH-TFA (50:50:1) by ultrasonication. The solutions were analyzed by chiral HPLC with a Chiralpak IC using a mixture of hexane-EtOH-TFA (80:20:0.1) as solvent. By comparison with authentic D or L monosaccharide samples, the configurations were identified as D-glucose (Rt 19.3 and 24.5).

3.5. 28-O- $\beta$-D-glucopyranosyl-2 $\alpha, 3 \beta, 21 \beta, 23$-tetrahydroxyolean-18-en-28-oate (1) 
White amorphous powder, $[\alpha]^{20}{ }_{\mathrm{D}}+21.2(c$ 0.11, $\mathrm{MeOH}) ;{ }^{1} \mathrm{H}$ and ${ }^{13} \mathrm{C} \mathrm{NMR}\left(\mathrm{MeOH}-d_{4}\right)$

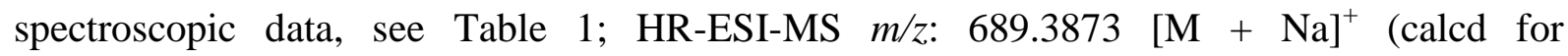
$\left.\mathrm{C}_{36} \mathrm{H}_{58} \mathrm{O}_{11} \mathrm{Na}, 689.3877\right)$.

\subsection{Broth diffusion antibacterial assays.}

The liquid microdilution growth inhibition method was used to determine the MIC values of the actives compounds $\mathbf{1}, \mathbf{3}, \mathbf{5}, \mathbf{9}$ and $\mathbf{1 1}$ against standard strains of $S$. aureus, E. faecalis and E. coli as described in [31]. Briefly, the mother compound solutions (10 mg/mL) were prepared by dissolving the compound in DMSO. Fifty microliters of each solution was added to $950 \mu \mathrm{L}$ of Muller-Hinton medium. This was serially diluted 2-fold with Muller-Hinton medium to obtain concentration ranges of 4 to $256 \mu \mathrm{g} / \mathrm{mL}$. Fifty microliters of each concentration was added in a well (96-well microplate) containing $150 \mu \mathrm{L}$ of Mueller-Hinton medium and $5 \mu \mathrm{L}$ of the standard inoculum. The final concentration of DMSO in the well was less than $5 \%$ (preliminary analysis with 5\% (v/v) DMSO/Mueller-Hinton medium affected neither the growth of the test organisms nor the change of color due to this growth). The negative control well consisted of $12.5 \mu \mathrm{L}$ of DMSO, 187.5 $\mu \mathrm{L}$ of Mueller-Hinton medium, and $5 \mu \mathrm{L}$ of the standard inoculum. The plates were covered with a sterile plate sealer, then agitated and incubated at $37{ }^{\circ} \mathrm{C}$ for $18 \mathrm{~h}$. Microbial growth was determined by observing the deposit of the bacteria at the bottom of the wells. The lowest concentration inhibiting bacterial deposit was considered as the MIC. The experiments were run in triplicate, and each time the MIC values were identical. Gentamicin was used as positive control in the same conditions.

\subsection{Cell proliferation assay.}

Promyelocytic leukemia HL-60 and human erythromyeloblastoid leukemia K562 cells were spread onto 96-well flat-bottom plates at a density of 2500 cells per well, and then incubated for $24 \mathrm{~h}$ in RPMI 1640 Medium supplemented with $10 \%$ fetal bovine serum and antibiotics. After culture, the cells were treated with saponins for $72 \mathrm{~h}$. The cell cultures were 
then analyzed using 3-(4,5-dimethylthiazol-2-yl)-5-(3-carboxymethoxyphenyl)-2-(4sulfophenyl)-2H-tetrazolium inner salt (MTS) according to the manufacturer's instructions (Promega Corporation, Charbonnières, France). Camptothecin was used as positive control with the same conduction. MTS is reduced by cells into a colored formazan product. Absorbance was analyzed at a wavelength of $540 \mathrm{~nm}$ with a Multiskan Ex microplate absorbance reader (Thermo Scientific, Paris, France). The results of these assays were used to obtain the dose-response curves from which $\mathrm{IC}_{50}$ values were determined. The values represent averages of three independent experiments.

\section{Acknowledgements.}

The authors are grateful to CNRS, Conseil Régional Champagne Ardenne, Conseil Général de la Marne, Ministry of Higher Education and Research (MESR), and to the PlANET CPER project for financial support.

\section{Supporting Information.}

HR-ESIMS and NMR data for compound 1-15.

\section{References}

[1] De Morais Lima, G.R., de Sales, I.R., Caldas Filho, M.R., de Jesus, N.Z., de Sousa, F.H., Barbosa-Filho, J.M., Guedes Silveira Cabral, A., Lopes Souto, A., Fechine Tavares, J., Batista, L.M. et al. Bioactivities of the genus Combretum (Combretaceae): a review. Molecules 2012; 17: 9142-206.

[2] Stace, C.A. The Families and Genera of Vascular Plants. Springer Berlin Heidelberg; 2007; 9: 67-82.

[3] McKeage, M.J.. Clinical trials of vascular disrupting agents in advanced nonsmall-cell lung cancer. Clin Lung Cancer 2011; 12: 143-147. 
[4] Okwuosa, C., Urekwe, P., Nwobodo, E., Chilaka, K. The antiulcer activities of leaf extracts of Combretum racemosum (Family; Combretacaeae). J. Biomed. Investig. 2006; 4: 9-14.

[5] Pettit, G.R., Singh, S.B., Niven, M.L., Hamel, E., Schmidt, J.M. Isolation, structure, and synthesis of combretastatins A-1 and B-1, potent new inhibitors of microtubule assembly, derived from Combretum caffrum. J. Nat. Prod. 1997; 50: 119-131.

[6] Burkill, H.M. The Useful Plants of West Tropical Africa. Royal Botanic Gardens. 1985; 1: $650-652$.

[7] Atindehou, K.K., Schmid, C., Brun, R., Kone, M.W., Traore, D.. Antitrypanosomal and antiplasmodial activity of medicinal plants from Côte d'Ivoire. J. Ethnopharmacol. 2004; 90: 221-227.

[8] Onocha, P.A., Audu, E.O., Ekundayo, O., Dosumu, O.O. Phytochemical and antimicrobial properties of extracts of Combretum racemosum. Acta. Hortic. 2005; 675 :97-101.

[9] Oliver-Bever B (1986). Medicinal Plants of Tropical West Africa. Cambridge University Press, London, p. 133.

[10] Babatunde, S.B., Moyinoluwa, O.O., Oluwatosin, A., Eigege, W., Shreyyans, K. Bioguided isolation of an antioxidant compound from Combretum racemosum P.Beav.leaf. Int. J. boil. Chem. Sci. 2014; 6:2339-2346.

[11] Eze, J.I., Anosa, G.N., Ozota, C.A. In vitro and in vivo trypanocidal activity of Combretum racemosum leaves. Afr. J. Biotechnol. 2012; 11: 10611-6.

[12] Nsuadi Manga, F., El Khattabi, C., Fontaine, J., Berkenboom, G., Duez, P., Lami Nzunzu, J., Pochet, S. Vascular effects and antioxidant activity of two Combretum species from Democratic Republic of Congo. J. Ethnopharmacol.2012; 142: 194-200. 
[13] Okwuosa, C.N., Achukwu, P.U.O., Azubike, N.C., Abah, A.I.E. Protective effect of the leaf extracts of Combretum racemosum P. Beauv (Combretaceae) on cyclophosphamide induced pancytopaenia and liver injury in male rats. Res. J. Pharmacol. 2012; 6: 30-34.

[14] Schepetkin, I.A., Kouakou, K., Yapi, A., Kirpotina, L.N., Jutila, M.A., Quinn, M.T. Immunomodulatory and hemagglutinating activities of acidic polysaccharides isolated from Combretum racemosum. Int Immunopharmacol. 2013 ; 15: 628-637.

[15] Kola, A., Ekpo, B. Comparative antimicrobial activities of the leaves of Combretum micranthum and Combretum racemosum. Global J Med Sci 2002; 1: 13-7.

[16] Omotayo, F.O., Borokini, T. I. Comparative phytochemical and ethnomedicinal survey of selected medicinal plants in Nigeria. Sci. Res. Essays. 2012; 7: 989-999.

[17] Agrawal, P.K. NMR spectroscopy in the structural elucidation of oligosaccharides and glycosides. Phytochemistry 1992; 31:3307-3330.

[18] Mahato, S.B., Kundu, A.K. ${ }^{13}$ C NMR Spectra of pentacyclic triterpenoids-a compilation and some salient features. Phytochemistry 1994; 37: 1517-1575.

[19] Bisoli, E., Silva Garcez, W., Hamerski, L., Tieppo, C., Rodrigues Garcez, F. Bioactive pentacyclic triterpenes from the stems of Combretum laxum. Molecules 2008; 13: 27172728.

[20] Li, J., Xu, H., Tang, W., Song, Z. Two new triterpenoids from the bark of Eucalyptus exserta and their molluscicidal and cytotoxic activities. Fitoterapia 2012; 83: 383-387.

[21] Nandy, A.K., Podder, G., Sahu, N.P., Mahato, S.B. Triterpenoids and their glucosides from Terminalia bellerica. Phytochemistry 1989; 28: 2796-2112.

[22] Jossang, A., Seuleimann, M., Maidou, E., Bodo, B. Pentacyclic triterpenes from Combretum nigricans. Phytochemistry 1996; 41: 591-594.

[23] Kundu, A.P., Mahato, S.B. Triterpenoids and their glycosides from Terminalia chebula. Phytochemistry 1993; 32: 999-1002. 
[24] Mahato, S.B., Nandy, A.K., Kundu, A.P. Pentacyclic triterpenoid sapogenols and their glycosides from Terminalia Bellerica. Tetraedron 1992; 48: 2483-2494.

[25] Song, Y.L., Zhang, L., Gao, J.M., Du, G.H., Cheng, Y.X. Speciosaperoxide, a new triterpene acid, and other terpenoids from Chaenomeles speciosa. J. Asian Nat. Prod. Res. 2008; 10: 214-217.

[26] Zhu, C.C., Gao, L., Zhao, Z.X., Lin, C.Z. Triterpenes from Callicarpa integerrima Champ. Acta Pharmaceutica Sinica 2012; 47: 77-83.

[27] Houghton, P.J., Lian, L.M. Triterpenoids from Desfontainia Spinosa. Phytochemistry 1986;.25: 1939-1944.

[28] Yano, I., Nishiizumi, C., Yoshikawa, K., Arihara, S. Triterpenoid saponins from Ilex integra. Phytochemistry 1993; 32:417-420.

[29] Yinusa, I., George, N.I., Amupitan, J.O. Isolation and bioactivity of pentacyclic triterpenoid (Betulinic acid) from the bark of Sarcocephalus latifolius (Smith Bruce). J. Nat. Sci. Res. 2012; 2: 13-23.

[30] Adnyana, I.K., Tezuka, Y.,. Banskota, A.H., Tran, K.Q., Kadota, S. Three new triterpenes from the seeds of Combretum quadrangulare and their hepatoprotective activity. J. Nat. Prod. 2001; 64: 360-363.

[31] Yao-Kouassi, P.A., Alabdul Magid, A., Richard, B., Martinez, A., Jacquier, M.J., Caron, C., Le Magrex Debar, E., Gangloff, S.C., Coffy, A.A., Zèches-Hanrot, M. Isoflavonoid glycosides from the roots of Baphia bancoensis. J. Nat. Prod. 2008; 71: 2073-2076. 